\title{
Duloxetine for treatment of male sphincteric incontinence following partial conus medullaris infarction after coronary bypass surgery
}

\author{
Sanjay Sinha*1, Sreenivasa R Sirigiri ${ }^{1}$, Srinivas K Kanakamedala1, \\ Manoj K Singh ${ }^{2}$ and Rakesh M Sharma ${ }^{1}$
}

\author{
Address: ${ }^{1}$ Department of Urology, Medwin Hospital, Chirag Ali Lane, Hyderabad-500001, India and 2Department of Neurology, Medwin \\ Hospital, Chirag Ali Lane, Hyderabad-500001, India \\ Email: Sanjay Sinha* - drsanjaysinha@hotmail.com; Sreenivasa R Sirigiri - sirigiri_sreenu@yahoo.com; \\ Srinivas K Kanakamedala - drsrinivaskumar@hotmail.com; Manoj K Singh - manksingh@gmail.com; \\ Rakesh M Sharma - rakeshms07@yahoo.com \\ * Corresponding author
}

Published: 26 November 2009

Cases Journal 2009, 2:9094 doi:10.1186/1757-1626-2-9094

This article is available from: http://www.casesjournal.com/content/2/I/9094

(c) 2009 Sinha et al; licensee BioMed Central Ltd.

This is an Open Access article distributed under the terms of the Creative Commons Attribution License (http://creativecommons.org/licenses/by/2.0), which permits unrestricted use, distribution, and reproduction in any medium, provided the original work is properly cited.
Received: 3 August 2009

Accepted: 26 November 2009

\begin{abstract}
Introduction: Vascular spinal cord injury following coronary bypass grafting surgery is very rare and this is probably one of few reports of a presumptive partial conus medullaris lesion leading to sudden onset bladder and bowel incontinence which was managed using duloxetine, a selective serotonin and norepinephrine reuptake inhibitor. Duloxetine has been used in selected patients with post-prostatectomy sphincteric incontinence but not, to our knowledge, for spinal vascular lesions.

Case presentation: A 63-year-old Indian man developed bladder and bowel incontinence immediately following coronary bypass grafting surgery. Findings were suggestive of microcirculatory partial conus medullaris infarction. Based on his urodynamics findings he was managed with duloxetine, tolterodine and clean intermittent catheterization. The clinical presentation, serial urodynamic findings and implications are discussed.

Conclusion: Spinal injury following coronary bypass grafting is rare and devastating. It is important to be able to recognize the problem even when paraplegia is not noted, counsel the patient and manage the patient with the help of urodynamics. In patients with sphincteric incontinence, duloxetine may have a role in management.
\end{abstract}

\section{Introduction}

Vascular spinal cord injury following coronary artery bypass grafting surgery (CABG) is very rare $[1,2]$ and this is probably one of few reports of a presumptive conus medullaris lesion leading to sudden onset bladder and bowel incontinence. Our patient was managed using duloxetine, a selective serotonin and norepinephrine reuptake inhibitor with clean intermittent self catheterization (CISC). Duloxetine has been used for post-prostatectomy incontinence in men and is approved for female stress urinary incontinence in many countries [3]. The drug works by increasing the rhabdosphincter tone via a 


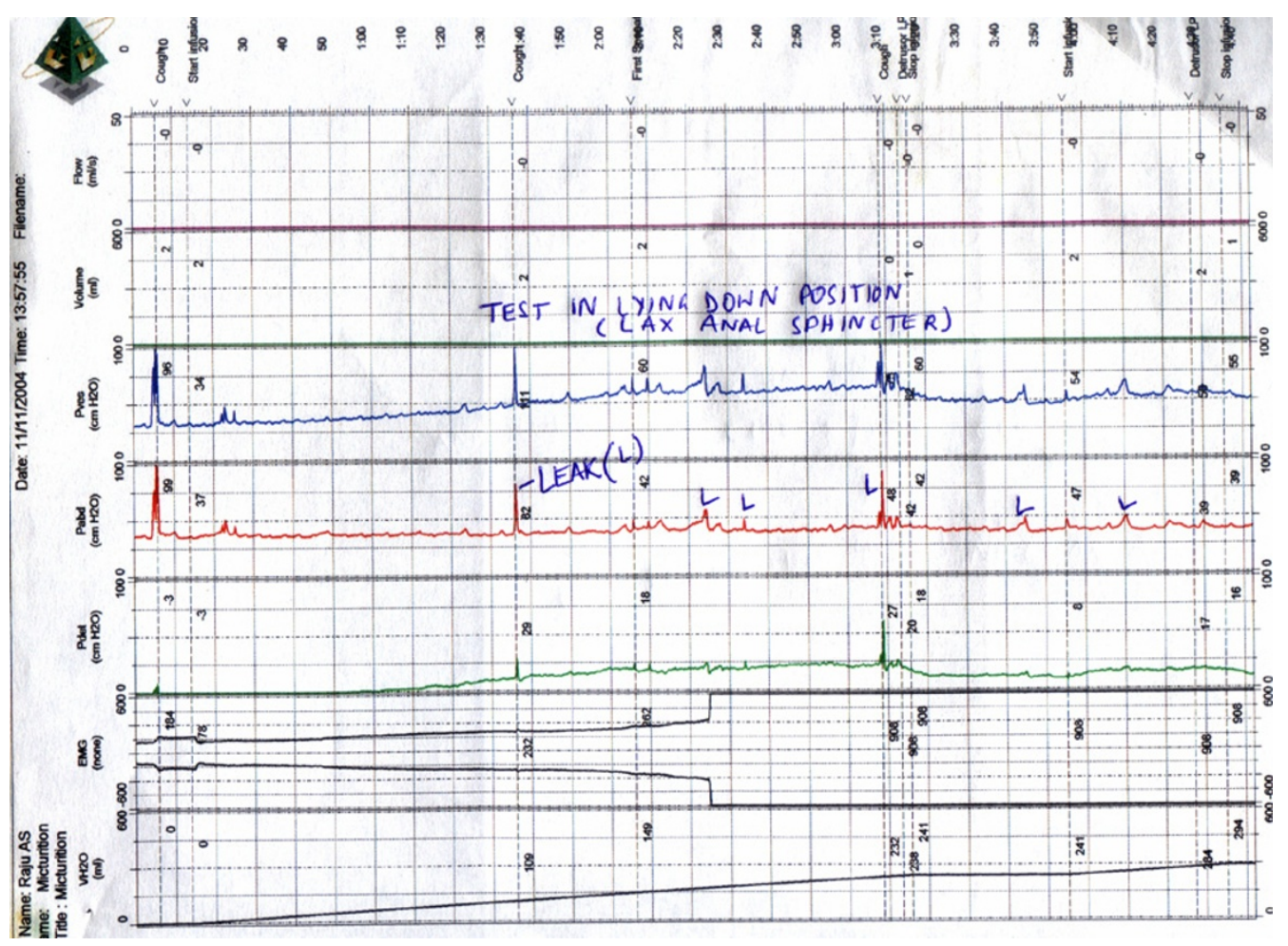

\section{Figure I}

Initial urodynamics study. Urodynamic study prior to duloxetine (Nov 2004, 4 months after onset) done in lying down position (since the patient had a very lax anal sphincter). There was severe leak (L) noted on minimal abdominal straining. Continuous pericatheter leak was noted at $225 \mathrm{ml}$ at a pressure of $19 \mathrm{~cm} \mathrm{H} 20$. He had an acontractile detrusor.

spinal cord mediated action [3]. To our knowledge, there is no literature on the use of duloxetine for neurogenic sphincteric male urinary incontinence.

\section{Case Presentation and Management}

A 63y hypertensive, non-smoker male underwent CABG in July 2004. He was non-diabetic, had no prior neurological problems and had a normal lipid profile. He had mild urinary frequency prior to CABG. Immediately following CABG he developed both bladder and bowel incontinence. Ultrasonographic examination showed $150 \mathrm{ml}$ urine in the bladder with inability to void suggesting a picture of overflow incontinence albeit with a reduced capacity. He had profound laxity of anal sphincter, distended rectum with stool impaction, impaired perianal sensation and absent bulbocavernosal reflex but no lower limb neurological symptoms. There was isolated bladder and bowel involvement without a well defined spinal shock. Lower limb reflexes were intact and normal. Spinal MR imaging did not show any abnormality. The clinical findings were consistent with probable microcirculatory ischemic infarction of the conus medullaris region leading to partial and selective denervation.
He had recurrent retention for which he underwent urodynamics evaluation at 4 months. This showed mild reduction in compliance, no phasic contractions, and leak after $225 \mathrm{ml}$ filling at a detrusor leak point pressure of 19 $\mathrm{cm} \mathrm{H} 20$. He had severe incontinence with any rise in abdominal pressure suggesting low sphincteric resistance (Figure 1). He was unable to empty the bladder effectively on a Crede's maneuver and was started on CISC, tolterodine and imipramine. He continued to have urinary incontinence between catheterizations. He was then started on duloxetine $40 \mathrm{mg}$ twice daily along with tolterodine. This resulted in complete resolution of his incontinence, increase in average CISC volumes from $150 \mathrm{ml}$ to $280 \mathrm{ml}$, with marked improvement in urodynamics parameters (Figure 2).

At 5 years followup the patient continues CISC and medication and is doing well.

\section{Discussion}

Conus medullaris ischemia and infarction with profound loss of anal sphincter tone and bowel and bladder incontinence [4] has been reported following aortic surgery due to intraoperative insult to vascular supply [5]. The clinical 


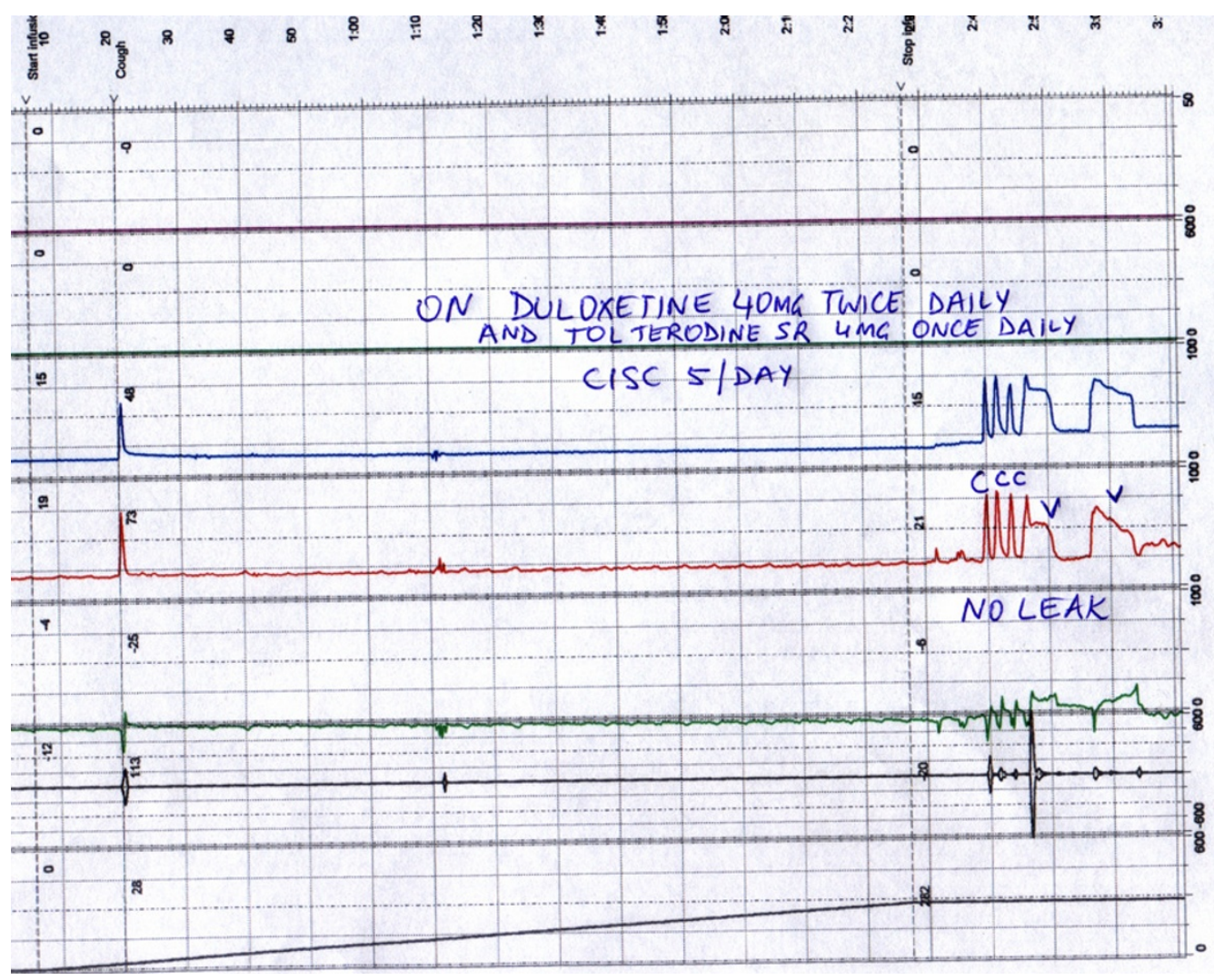

\section{Figure 2}

Follow up urodynamics study. Follow up urodynamic study after commencing $40 \mathrm{mg}$ twice daily Duloxetine (Aug 2005). Patient also on tolterodine sustained release $4 \mathrm{mg}$ once daily. No leak was observed on cough $(\mathrm{C})$ or valsalva $(\mathrm{V})$ and there was no pericatheter leak on filling beyond $400 \mathrm{ml}$ (not depicted; separate cycle of filling).

presentation of this patient strongly suggests the occurrence of microcirculatory partial conus medullaris infarction. Microcirculatory infarction is well known in a post operative setting and may not be identifiable on conventional imaging [2].

Duloxetine is approved for use in men for its neuropsychiatric effects [6]. Conceptually, the rhabdosphincter effects of duloxetine seen in women should be reproducible in men. Increased serotonin and norepinephrine availability due to duloxetine has been shown in healthy volunteer men at clinical dosages [7]. In fact, retention has been reported in men using the drug for psychiatric indications [6]. In our patient tolterodine was used along with duloxetine to reduce the storage bladder pressures and improve functional bladder capacity. The safety of this combination has already been documented and no dosage adjustments are necessary [8]. There are initial reports on the use of duloxetine for post-prostatectomy male urinary incontinence [9]. Duloxetine was found to be effective but there were significant side effects necessitating stoppage of drug in 6 out of the 20 patients studied. In our patient with a neurogenic male sphincteric incontinence, presumably the duloxetine worked by increasing the tone of the external rhabdosphincter by increasing neurotransmitter availability. This might have been possible because the patient had a partial conus lesion. Future studies are needed to evaluate the use of this drug in neurogenic male sphincteric incontinence to identify whether the drug would be effective in all forms of neurogenic sphincteric incontinence or only in select patients with incomplete lesions.

\section{Conclusion}

Spinal injury following CABG is very rare. It is important to be able to recognize lower urinary tract dysfunction even when paraplegia is not noted, counsel the patient and manage the patient with the help of urodynamics. In patients with neurogenic sphincteric incontinence, duloxetine may have a role in management.

Institutional ethics committee approval was taken prior to use of duloxetine in this patient. 


\section{Abbreviations}

CABG: Coronary artery bypass grafting; CISC: Clean intermittent self catheterization.

\section{Consent}

Written informed consent was obtained from the patient for publication of this case report and accompanying images. A copy of the written consent is available for review by the Editor-in-Chief of this journal.

\section{Competing interests}

The authors declare that they have no competing interests.

\section{Authors' contributions}

SS analysed and interpreted the report. SSR analysed and interpreted the report. KSK was a major contributor in writing the manuscript. MKS analysed and interpreted the report. RS was a major contributor in writing the manuscript. All authors read and approved the final manuscript.

\section{References}

I. Rossi D, Goodwin D, Cruzzavala J: Spinal cord infarction following coronary artery bypass grafting surgery. W V Med J 2008, 104:24-5.

2. Gottesman MH, Saraya I, Tenti F: Modified Brown-Séquard syndrome following coronary artery bypass graft: case report. Paraplegia 1992, 30: 178-80.

3. Ghoniem GM, Van Leeuwen JS, Elser DM, Freeman RM, Zhao YD, Yalcin I, Bump RC: A randomized controlled trial of duloxetine alone, pelvic floor muscle training alone, combined treatment and no active treatment in women with stress urinary incontinence. J Urol 2005, 173:1647-1653.

4. Anderson NE, Willoughby EW: Infarction of the conus medullaris. Ann Neurol 1 987, 21 : 470-4.

5. Dougherty MJ, Calligaro KD: How to avoid and manage nerve injuries associated with aortic surgery: ischemic neuropathy, traction injuries, and sexual derangements. Semin Vasc Surg 200I, I 4:275-8I.

6. Viktrup L, Pangallo BA, Detke MJ, Zinner NR: Urinary side effects of duloxetine in the treatment of depression and stress urinary incontinence. Prim Care Companion J Clin Psychiatry 2004, 6:65-73.

7. Chalon SA, Granier LA, Vandenhende FR, Bieck PR, Bymaster FP, Joliat MJ, Hirth C, Potter WZ: Duloxetine increases serotonin and norepinephrine availability in healthy subjects: a double blind, controlled study. Neuropsychopharmacology 2003, 28:1685-1693.

8. Hua TC, Pan A, Chan C, Poo YK, Skinner MH, Knadler MP, Gonzales $\mathrm{CR}$, Wise SD: Effect of duloxetine on tolterodine pharmacokinetics in healthy volunteers. Br J Clin Pharmacol 2004, 57:652-656.

9. Schlenker B, Gratzkea C, Reicha O, Schorscha I, Seitza M, Stiefa CG: Preliminary Results on the Off-Label Use of Duloxetine for the Treatment of Stress Incontinence after Radical Prostatectomy or Cystectomy. Eur Urol 2006, 49: 1075- 1078.
Publish with Biomed Central and every scientist can read your work free of charge

"BioMed Central will be the most significant development for disseminating the results of biomedical research in our lifetime. "

Sir Paul Nurse, Cancer Research UK

Your research papers will be:

- available free of charge to the entire biomedical community

- peer reviewed and published immediately upon acceptance

- cited in PubMed and archived on PubMed Central

- yours - you keep the copyright

Submit your manuscript here:

http://www.biomedcentral.com/info/publishing_adv.asp
BioMedcentral 